\title{
A Rare Case Report in the Geriatric Practice: Kaposi's Sarcoma
}

\author{
Rabia Bag Soytas, Ayse Gul Satman Durmaz, Serdar Ozkok, Suna Avci and Alper Doventas* \\ Department of Internal Medicine, University of Istanbul, Turkey
}

*Corresponding author: Alper Doventas, Department of Internal Medicine, Division of Geriatrics, University of Istanbul, Cerrahpasa Medical School, Turkey

Submission: July 24, 2018; Published: August 14, 2018

\begin{abstract}
Classical Kaposi's sarcoma is a rare condition, which is seen in men, especially those of Mediterranean and Jewish, between ages of 40-70 and has a good prognosis. In this case report, our aim is to emphasize the atypical presentation of the classical type of Kaposi's sarcoma, which was developed in a 91-year-old female patient. Although nutritional factors have been associated mostly with acquired immunodeficiency syndrome-related or endemic type of Kaposi sarcoma; the low score of our patient's mini-nutritional assessment (MNA) (17 points) suggests that nutrition status may also play a role in the development of a classical type of Kaposi sarcoma.
\end{abstract}

\section{Background}

Kaposi sarcoma was first described by Moriz Kaposi in 1872 $[1,2]$. According to clinical and epidemiological characteristics, there are four basic types of Kaposi sarcoma: epidemic or AIDS-related, immuno suppressed, classical and endemic (African type [3]. Nutritional factors are mostly related to acquired immunodeficiency syndrome-related, or epidemic type [4]. The classical type has the best prognosis and is seen in men between the ages of 40 and 70, especially those of Mediterranean and Jewish [5]. Kaposi's sarcoma progresses slowly; it presents as red-purple maculae and patches in distal of lower-limbs at early stages; and later, it progresses to nodular lesions or vegetative masses [6]. We wanted to emphasize the atypical presentation of classical type Kaposi's sarcoma, which developed in a 91-year-old female.

\section{Case Report}

Our case is a 91-year-old female patient, who complained about erythematus, painful injuries on both of her lower extremities for almost 6 months. According to her statements, the lesions tended to grow further in time and she also had a fever at later stages. There was no other illness in her medical or family history. According to mini nutritional assessment (MNA), the patient had malnutrition (she received 17 points out of 30 ).

In her physical examination, body temperature was $38^{\circ} \mathrm{C}$, blood pressure and pulse rates were normal. There were 2 lesions on the medial side of the right foot, 1 lesion on the left side; which are about $2-3 \mathrm{~cm}$ and regular margined. Also, the lesions were superficial, ulcerous and painful, slightly erythematous and covered with dry fibrin coat (Figure 1). In her laboratory tests, there were neu trophilic leukocytosis (WBC: $12.500 \mathrm{~mm}^{3}$, neutrophil: $7900 \mathrm{~mm}^{3}$ ) and elevated acute phase reactants (Crp: $97 \mathrm{mg} / \mathrm{dL}$, sedimentation: $57 \mathrm{~mm} / \mathrm{h}$ ). The anti-HIV antibody test was negative. The rheumatological markers in terms of vasculitis (C-ANCA/ P-ANCA/ MPO-ANCA/PR3-ANCA) were also negative. At the peripheral blood smear examination, $10 \%$ of leucocytes showed as band cells, $55 \%$ were segmented neutrophils, 5\% were monocytes, 25\% lymphocytes, $5 \%$ eosinophils. Platelets were sufficient and erythrocytes were recorded as nor mochromic normocytic. Arterial blood supply was decreased in both lower extremities due to the advanced age, according to arterial doppler ultrasonography. Piperacillin-tazobactam and teicoplanin sensitive Providencia rettgeri colonies were isolated in the deep tissue culture.

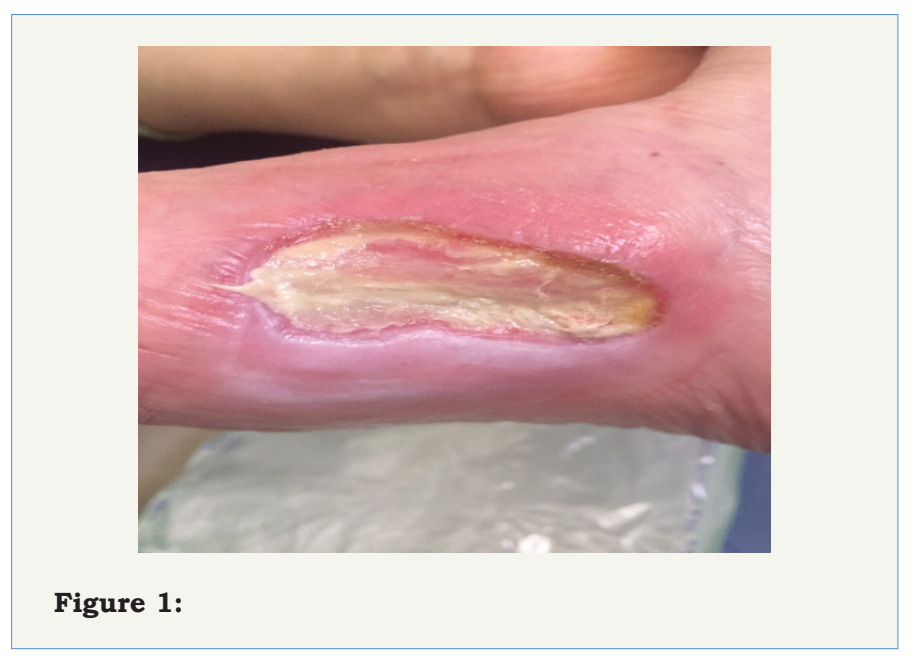


Histopathological examination showed fibrinoid substances in lumen and walls of some vessels, prominent vessel proliferation, characterized by neutrophil, polymorph, and nucleus fragments; Morphologically, a vascular pathology (thrombus?) was first thought to be a secondary vasculopathy. Because a focally disorganized endothelial architecture is detected, immuno histochemical stain for HHV-8 is applied and a focal HHV-8 positive area was found then. Therefore, the lesion was thought to be compatible with lymphangioma-like Kaposi sarcoma. The deep tissue biopsy concluded as Kaposi's sarcoma.

PET-CT was taken to look for systemic involvement. Focal malignant FDG accumulations were detected on the medial plantar surface of the right foot, the lateral side of the left foot and posterior of the left heel (Figure 2). As a result, the patient was diagnosed as locally advanced, classical type of Kaposi's Sarcoma and radiotherapy plan was done for the treatment.

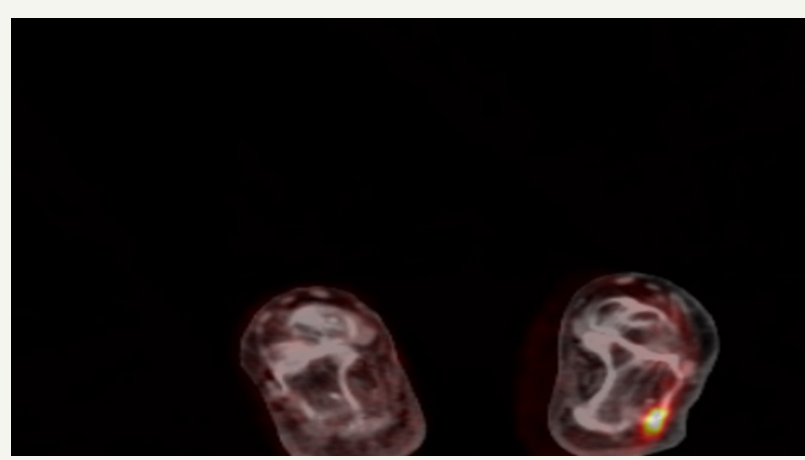

Figure 2:

\section{Conclusion}

Kaposi's sarcoma-classical type is a rare condition and usually occurs in older men in the form of painless, red-violet macules and patches that settle in the lower extremities $[7,8]$. Our patient differs from usual cases because of gender, older age, her atypical and painful lesions and the absence of other common Kaposi's sarcoma etiologies (diabetes, malignancy, HIV, any disease-causing immuno suppression, etc.). A lymphangioma type of Classical Kaposi's sarcoma; which is very rare (less than $5 \%$ of all Kaposi's sarcoma) and known to respond well to radiotherapy even in the advanced stag- es, should be considered in geriatric cases in such resistant wounds $[9,10]$. Although nutritional factors have been associated with acquired immunodeficiency syndrome-related or endemic type; the low score of our patient's MNA (17 points) suggests that malnutrition may also play a role in the occurrence of a classical type of Kaposi's sarcoma. Lower hemoglobin and hematocrit values have describedsignificantly lower among patients with CKS as compared with controls without the disease in two studies [11,12]. This also suggest that classic Kaposi's sarcoma may be related to nutrition.

\section{References}

1. Chang Y, Moore P (2014) Twenty years of KSHV. Viruses 6(11): 42584264.

2. Radu O, Pantanowitz L (2012) Kaposi sarcoma. Arch Pathol Lab Med 137(2): 289-294.

3. Lanternier F, Lebbé C, Schartz N, Farhi D, Marcelin AG, et al. (2008) Kaposi's sarcoma in HIV-negative men having sex with men. AIDS 22(10): 1163-1168.

4. Colman N, Grossman F (1987) Nutritional factors in epidemic Kaposi's sarcoma. Semin Oncol 14(2 Suppl 3): 54-62.

5. Schwartz RA (2004) Kaposi's sarcoma: an update. J Surg Oncol 87(3): 146-151.

6. Buonaguro FM, Tornesello ML, Buonaguro L, Satriano RA, Ruocco E, et al. (2003) Kaposi's sarcoma: aetiopathogenesis, histology, and clinical features. J Eur Acad Dermatol Venereol 17(2): 138-54.

7. Atzori L, Fadda D, Ferreli C, Pastorelli C, Iannelli P, et al. (2004) Classic Kaposi's sarcoma in southern Sardinia, Italy. Br J Cancer 91(7): 12611262.

8. Doğan GB, Bahadir B, Ekem TE, Numanoglu G, Gün MÖ, et al. (2007) Classical Kaposi's sarcoma: Clinical and immuno histochemical features. Turkey Clinical J Dermatol 17: 21-25.

9. Cossu S, Satta R, Cottoni F, Massarelli G (1997) Lymphangioma-like variant of Kaposi's sarcoma: clinicopathologic study of seven cases with review of the literature. Am J Dermatopathol 19: 16-22.

10. Pantanowitz L, Duke WH (2008) Lymphoedematous variants of Kaposi's sarcoma. J Eur Acad Dermatol Venereo 22: 118-120.

11. Brown EE, Whitby D, Vitale F (2006) Virologic, hematologic, and immunologic risk factors for classic Kaposi sarcoma. Cancer 107: 2282.

12. Touloumi G, Hatzakis A, Potouridou I (1999) The role of immuno suppression and immune-activation in classic Kaposi's sarcoma. Int J Cancer 82: 817.
Creative Commons Attribution 4.0 International License

For possible submissions Click Here

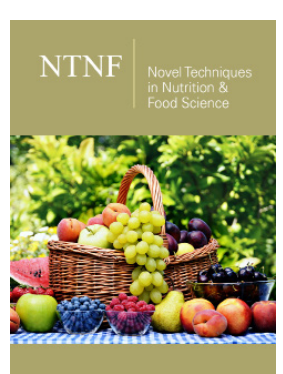

Novel Techniques in Nutrition and Food Science

\section{Benefits of Publishing with us}

- High-level peer review and editorial services

- Freely accessible online immediately upon publication

- Authors retain the copyright to their work

- Licensing it under a Creative Commons license

- Visibility through different online platforms 